\title{
A IMPORTÂNCIA DO DEPARTAMENTO DE TECNOLOGIA DA INFORMAÇÃO PARA AS ORGANIZAÇÕES: UM ESTUDO DE CASO
}

Giovana Rocha Pires, Leandro Esmerdel, Vitória Oliveira, Wesley Alves, Ivan Marcio Gitahy Junior.

${ }^{1}$ Universidade do Oeste Paulista - UNOESTE, ${ }^{2}$ Senac Presidente Prudente. Presidente Prudente/SP. E-mail: ivan@unoeste.br.

\section{RESUMO}

Observando as necessidades da sociedade e do mercado atual em relação a tecnologia e seus avanços, será abordado neste projeto a importância do departamento de tecnologia da informação para facilitar e melhorar o desempenho do trabalho executado pelas organizações. Identificando as características dos profissionais da área e sua atuação em toda a empresa, seu diferencial é a atuação junto ao departamento estratégico e a eficácia que ele traz a realização das tarefas. Para isso será analisado a empresa " $x$ ", por meio de entrevistas e coletas de dados para analisar e comprovar a importância do departamento após sua implantação na empresa.

Palavras-chave: Tecnologia. Departamento de Tecnologia da informação. Organizações. Atuação estratégica.

\section{THE IMPORTANCE OF THE INFORMATION TECNOLOGY DEPARTMENT FOR THE ORGANIZATIONS:} A CASE STUDY

\begin{abstract}
Noting the needs of society and the current market in relation to technology and its advances, it will be addressed in this project the importance of the information technology department to facilitate and improve the performance of the work performed by the organizations. Identifying the characteristics of professionals and its activities across the enterprise, its differential is the performance in the strategic department and effectiveness it brings the tasks. For it will be analyzed the company " $x$ " through interviews and data collection to analyze and demonstrate the importance of the department after its implementation in the company.
\end{abstract}

Keywords: Technology. Department of Information Technology. Organizations. strategic performance. 


\section{INTRODUÇÃO}

No decorrer das últimas décadas a sociedade passou por um processo de transformação que foi denominado como globalização. Pessoas, empresas e países de todo o mundo, passaram a interagir construindo relações econômicas, como transações financeiras e comerciais e relações culturais por meio da disseminação das culturas. Essa interação fez com que encurtassem as distâncias entre os países, uma empresa brasileira poderia criar laços econômicos com uma empresa do Japão sem o contato pessoal, por exemplo, obviamente essa aproximação só foi possível pelas tecnologias que facilitaram a comunicação, a Internet é a principal delas.

Tendo esse contexto em mente, é possível entender o motivo pelo qual as empresas passaram a investir mais em tecnologias de comunicação e informação, e por entender que isso influenciou nos resultados da organização não se acomodaram e continuam se atualizando constantemente às novidades tecnológicas já que estas surgem em uma velocidade alta no mercado.

Esta pesquisa tem como propósito auxiliar empresários que ainda não possuem uma unidade de TI em sua organização e que desejam implantá-la, demonstrando como o departamento de TI pode auxiliar na estratégia empresarial de uma empresa.

\section{METODOLOGIA}

Neste item serão apresentados os passos necessários para a realização da pesquisa, todos os métodos e instrumentos que foram utilizados.

De acordo com Santos e Noronha (2005, p. 56) “[...] a metodologia consiste na definição de onde, como (campo de observação), com o que (instrumento) e quanto (utilização de provas estatísticas para demonstrar os resultados) [...]".

Segundo Ander-Egg (apud MARCONI; LAKATOS 2010) a pesquisa é o conjunto de procedimentos reflexivos e sistemáticos, que proporciona o descobrimento de novos fatos, informações, relações, nos mais diversos campos.

Os instrumentos de uma pesquisa científica são as técnicas utilizadas para coletar os dados que comprovem a verdade da pesquisa.

Para esta forma de estudo são encontrados dois tipos pesquisas, a básica que se caracteriza pela busca de informações e conhecimentos básicos para a elaboração de respostas solicitadas pelo trabalho, investigando fenômenos físicos e seus fundamentos.

E a aplicada que utiliza os conhecimentos adquiridos com a pesquisa básica para chegar a resultados consistentes e solucionar os problemas, "[...] o investigador é movido pela necessidade de contribuir para fins práticos mais ou menos imediatos, buscando soluções para problemas concretos" (CERVO, BERVIAN, SILVA, 2007, p.60).

Seguindo este pensando busca-se formar a pesquisa por meio da natureza aplicada, pois ela tem como objetivo solucionar problemas baseados em conhecimentos já produzidos, envolvendo a realidade da sociedade local.

Uma das formas utilizadas para coleta de dados será a entrevista, em segundo momento será utilizado à pesquisa bibliográfica para agregar conteúdo à realização da mesma, sendo considerado o norte do trabalho. Essa pesquisa é importante para o começo de um novo projeto, pois lhe permite saber se sua proposta já não foi apresentada anteriormente, oferece um conhecimento irreverente, pelo fato de ser possível encontrar opiniões de autores diferentes até mesmo de dados complexos que não necessita muitas explicações, por meio de diversas fontes de dados, permitindo uma pesquisa ampla e definitiva, se baseada em fontes confiáveis, podendo também ser considerada uma documental.

Elaborada de maneira descritiva, a fim de proporcionar novas visões sobre determinado assunto, visto que ela estuda temas já conhecidos, onde por meio de diversas 
análises, o tema pode ser aplicado em diferentes situações ou estudos de casos, tornando possível novas interpretações e aplicações. Segundo o autor JUNG (2003, p.125), entende-se que;

A pesquisa descritiva tem por finalidade observar, registrar e analisar os fenômenos sem, entretanto, entrar no mérito do seu conteúdo. Na pesquisa descritiva não há interferência do pesquisador, que apenas procura descobrir, a frequência com que o fenômeno acontece.

E por fim o objetivo explicativo que tem o foco voltado para explicar o porquê, a razão dos fatos relacionados aos fenômenos, a partir do objeto estudado realiza-se reflexões, análises e interpretações para poder identificar as causas dos fatos; devido o seu aprofundamento ao conhecimento da realidade, aumenta a probabilidade de erros, porém não faz com que perca sua relevância nos projetos, pois geralmente são utilizados nas buscas pelas explicações científicas.

Com isso, percebe-se que este estudo trata-se de uma pesquisa descritiva, pois descreverá as características do departamento de Tecnologia da Informação estabelecendo uma relação entre as variáveis existentes dentro da organização e as variáveis obtidas no estudo de caso.

Encontra-se dois tipos de abordagem em pesquisas científicas, a pesquisa qualitativa que consiste no levantamento de dados, levando como base a opinião popular sobre determinado assunto, de forma a questionar diretamente as pessoas e considerar sua opinião para formar o resultado, levando em consideração apenas o conteúdo das respostas, por isso é essencial que se tenham especialistas como parte dos consultados e questionados.

E a pesquisa quantitativa que tem como base coletar dados a partir de respostas populares, é necessário que os questionamentos estejam de forma clara, pois o resultado será formulado de forma estatística, baseado na quantidade/números de respostas. "[...] significa quantificar opiniões, dados, nas formas de coleta de informações, assim como também com o emprego de recursos e técnicas estatísticas [...] (OLIVEIRA, 1999, p.115)".

Desta forma, na presente pesquisa, será utilizado o método de abordagem quantitativa, ou seja, o estudo será baseado em dados mensuráveis, por meio de entrevistas, questionários, etc.

Um outro procedimento técnico também, seria o estudo de caso que é um instrumento utilizado pelo aluno com objetivo de fazer um levantamento de problemas e procurar soluções. Pode ser usado de forma organizacional, com intuito de auxiliar na tomada de decisão, de forma a diminuir chances de fracasso. O procedimento documental ajuda a incrementar informações que já fazem parte do projeto, com um aspecto inovador consente com o uso da criatividade e imaginação novos enfoques durante a pesquisa, vale a ressalva de que é uma técnica considerável para as áreas de ciências sociais e humana, "Quando envolve o estudo profundo e exaustivo de um ou poucos objetos de maneira que se permita o seu amplo e detalhado conhecimento" (JUNG, 2003, p.132).

Neste estudo será usado o estudo de caso como meio técnico, onde será avaliada uma empresa localizada em Presidente Prudente/SP.

\section{DESENVOLVIMENTO}

A tecnologia é a junção de conhecimentos, que na pratica é usado para trazer eficiência e eficácia na realização das tarefas. Para Kenski (2003, p. 18), "segundo o Dicionário de filosofia de Nicola Abbagnano (1982), a tecnologia é o estudo dos processos técnicos de um determinado ramo de produção industrial ou de mais ramos".

A informação desenvolve as ideias dos indivíduos, abrindo portas para outras e diferentes formas de pensar, por meio da compreensão e conhecimento de diferentes pensamentos que ajudando no desenvolvimento dos seus. Segundo Rezende e Abreu (2013) a informação torna a comunicação, coordenação e controle dos indivíduos mais eficientes, 
auxiliando na capacitação dos conhecimentos dos mesmos, a fim de alcançar os objetivos da organização.

Com a globalização, a tecnologia passa a ser algo cada vez mais presente na realidade das organizações, com esse novo ambiente sendo formado, surgiram novos tipos de profissionais, os mesmos que vieram em busca de auxiliar as organizações com esse constante avanço. Dentre esses novos profissionais no mercado de trabalho, encontra-se o profissional de $\mathrm{TI}$.

Para atender à complexidade e às necessidades empresariais, atualmente não se pode desconsiderar a Tecnologia da Informação e seus recursos disponíveis, sendo muito difícil elaborar Sistemas de Informação essenciais da empresa sem envolver esta moderna tecnologia. (REZENDE, ABREU; 2013, p.53)

O profissional de $\mathrm{TI}$ tem como principal objetivo criar, desenvolver e administrar formas de facilitar a rotina da organização, atendendo a todos os departamentos como uma assessoria (staff). Suas principais funções é orientar a área operacional com a administração de servidores e redes; assegurando também a segurança dos dados da empresa, evitando hackers; controla a situação dos ativos (computadores e softwares) da empresa, mantendo sempre atualizados com o contexto da organização.

Já na área estratégica da organização busca auxiliar as tomadas de decisões por meio de relatórios relevantes e levantamento de gráficos, ajudando os gestores a criar estratégias tecnológicas, sendo assim mais eficazes, acompanhando o desenvolvimento e mantendo a organização atualizada no mercado. "[...] sua principal finalidade e utilidade, que é o desenvolvimento e a melhoria dos Sistemas de Informação, para auxiliar a empresa em seus negócios, processos e atividades" (REZENDE, ABREU, 2013, p.54).

$\mathrm{Na}$ empresa pesquisada, uma das ferramentas que o TI disponibiliza para auxiliar na tomada de decisão, é o relatório em que constam os produtos mais vendidos e os menos vendidos. Esse relatório é o ponto de partida para o desenvolvimento de uma estratégia para reverter os números referentes ao produto menos vendido.

De maneira geral na organização, o profissional de TI busca facilitar o trabalho humano, por meio de novos ou aprimorados processos e ferramentas, tornando a realização das tarefas mais eficazes, reduzindo os gastos e atendendo com mais precisão a demanda e as necessidades do mercado.

A empresa em que a pesquisa foi realizada é uma organização industrial, com sede localizada na cidade de Presidente Prudente, São Paulo, a $560 \mathrm{~km}$ da capital. Sua trajetória no mercado teve início em 1989, com o lançamento do primeiro modelo do seu produto, na época contava apenas com os sócios e dois colaboradores, a partir daí, a empresa foi aos poucos, ganhando espaço no mercado do seu segmento e passou a diversificar seu portfólio de produtos.

Em 2016, com 27 anos de história a organização passou por uma grande transformação, hoje conta com mais de 350 funcionários e com um parque industrial de $8.000 \mathrm{~m}^{2}$ de instalações construídos, se tornou uma das mais importantes indústrias do setor, nas Américas, conquistou dois importantes prêmios nacionais e um Recorde internacional, e este contribuiu para o início da exportação dos seus produtos para mais de 45 países pelo mundo, além de uma filial nos Estados Unidos que auxilia na agilização do atendimento aos demais países em que os produtos da empresa são comercializados.

É composta por aproximadamente 28 departamentos, dentre eles o de Tecnologia da Informação, o qual foi o tema deste estudo, e que, de acordo com um dos analistas de sistema, o departamento existe na empresa há aproximadamente 15 anos e a equipe é composta por cinco profissionais, que atuam com o objetivo de reduzir os custos gerados pela organização. 
Prezando sempre a satisfação dos clientes é uma organização que se preocupa com a qualidade de seus produtos, pois é por meio da qualidade que as metas organizacionais serão alcançadas.

Segue parte do Organograma da empresa.

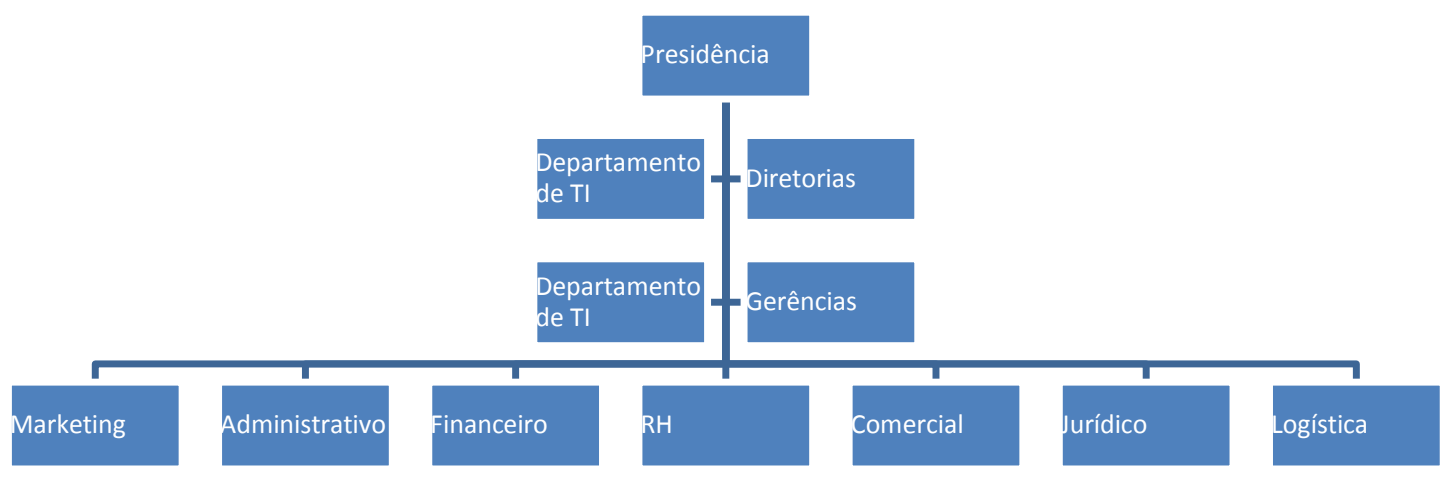

O organograma acima demonstra a importância do departamento de TI e sua integração com os demais departamentos da empresa, na tomada de decisão, na medida em que atua como uma ferramenta estratégica objetivando a permanência das organizações no mercado. Sua posição, logo abaixo da presidência e em ligação direta com a diretoria e gerências faz dela um elo fundamental para a organização. Tal posição propicia a empresa uma maior agilidade das informações e principalmente nas decisões a serem tomadas.

\section{RESULTADOS}

Baseados em um estudo de caso em uma organização que possui há 15 anos esse departamento, pode-se analisar que o mesmo trouxe as organizações um reforço não apenas em seu departamento operacional, mas principalmente em suas estratégias organizacionais, auxiliando a empresa com relatórios gerenciais capazes de orientar os gestores na tomada de decisão, desenvolvendo ferramentas que automatizam e tornam eficaz a realização de tarefas poupando o trabalho humano, reduzindo assim os custos da organização e trazendo um pensamento estratégico em busca do sucesso desejado pela mesma.

Diante deste pensamento, pode-se entender que o departamento de TI se localiza em uma linha de staff, de uma maneira que alcance todas as áreas, onde pode auxiliar nas necessidades dos departamentos, para que os mesmos consigam executar as tarefas a eles determinadas de forma eficiente e eficaz.

Mediante este estudo, evidencia-se a relevância estratégica que o departamento de $\mathrm{TI}$ traz a organização " $x$ " como citado acima, por meio da apresentação de sua atuação, a identificação de seus objetivos, a análise de sua influência e da praticidade alcançada pelo seu trabalho.

\section{CONCLUSÃO}

$\mathrm{Na}$ unidade de TI são coletados dados internos importantes, em que é possível identificar o que é positivo e o que deve ser melhorado dentro da organização. Essas estatísticas servem de base para a tomada de decisões da empresa e estas, consequentemente, causarão efeitos no mercado, atingindo os concorrentes, consumidores e sociedade em geral que é de onde se espera que venham bons resultados.

Portanto, após toda a investigação realizada, por meio de análises, que culminaram em um estudo de caso referente à certa organização prudentina, é possível concluir que, sim, a 
unidade de Tecnologia da Informação traz grande relevância a estratégia organizacional de uma empresa, já que influencia na tomada de decisões.

\section{REFERÊNCIAS}

CERVO, A.L; BERVIAN, P. A.; SILVA, R. Metodologia cientifica. 6. ed. São Paulo: Pearson Prentice Hall, 2007.

Especial carreiras: saiba o que faz um gerente de TI. Disponível em <http://www.itforum365.com.br/noticias/detalhe/53992/especial-carreiras-saiba-o-que-faz-umgerente-de-ti> Acesso em 31.mar.2016

Gestor de Tl: o que faz na prática o profissional? Disponível em < http://mercadoemfoco.unisul.br/gestor-de-ti-o-que-faz-na-pratica-o-profissional-da-area/>

Acesso em 31.mar.2016.

IETEC - Instituto de Educação Tecnológica. Profissional de TI: visão de mercado. Disponível em < http://www.techoje.com.br/site/techoje/categoria/detalhe artigo/534> Acesso em 31.mar.2016.

JUNG, C. F.; Metodologia cientifica: ênfase em pesquisa tecnológica. 3.ed., 2003.

KENSKI, VANI M. Educação e tecnologias: o novo ritmo da informação. São Paulo: Papirus, 2003.

MARCONI, M. A.; LAKATOS, E. M. Fundamentos de metodologia cientifica. 7.ed. São Paulo: Editora Atlas S.A, 2010.

OLIVEIRA, S.L.; Tratado de metodologia cientifica: projetos de pesquisas, tgi, tcc, monografias, dissertações e teses. 2.ed. São Paulo: Editora Pioneira, 1999.

REZENDE, D. A.; ABREU, A. F.; Tecnologia da informação aplicada a sistemas de informação empresarias. 9.ed. São Paulo: Editora Atlas, 2013

SANTOS, C. R.; NORONHA, R. T. S. D. Monografias cientificas. São Paulo: AverCAMP, 2005. 